\title{
Organização do saber e mediação documental: do tratamento de periódicos de história a sua utilização em bibliotecas universitárias na França
}

Josiane Senié Demeurisse

Doctorante en Sciences de I'information et de la communication Université Paul Sabatier - Lerass 115 route de Narbonne 31077 Toulouse Cedex 4 France

Isabelle Fabre

Docteure en Sciences de l'information et de la communication. Professeur certifié en documentation -Université de Toulouse - Enfa Toulouse EducAgro

Cécile Gardiès

Maître de conférences en Sciences de I'information et de la communication Professeur certifié en documentation - Université de Toulouse - Enfa - Toulouse EducAgro

A colocação online de recursos eletrônicos tende a se multiplicar no seio das instituições e de suas bibliotecas e altera ao mesmo tempo as práticas profissionais de tratamento da informação e os usos tradicionais. 0 exemplo do tratamento documental de periódicos, na sua forma em papel como na sua forma digital é interessante mesmo se ele parece não ser uniformizado. Com efeito as práticas profissionais da colocação à disposição destes meios específicos de difusão de informação parecem diferentes segundo os dispositivos observados. Neste trabalho, dois espaços documentais distintos foram pesquisados através da análise da oferta de periódicos de história proposta aos usuários. Esta primeira parte do estudo permitiu abordar as práticas profissionais de documentalistas, no seu papel de mediação da informação produzida pelos periódicos. A segunda parte interessa-se pelos usuários deste meio de informação. 
Palavras- Chave: Mediação; organização do saber; sistema de informação; dispositivo documentário; uso;periódico.

\section{Organisation du savoir et médiation documentaire : du traitement des périodiques d'histoire à leur usage en bibliothèques universitaires en France}

La mise en ligne des ressources électroniques tend à se multiplier au sein des institutions et de leurs bibliothèques et bouleverse à la fois les pratiques professionnelles de traitement de l'information et les usages traditionnels. L'exemple du traitement documentaire des périodiques, dans leur forme papier comme dans leur forme numérique est intéressant même s'il semble ne pas être uniformisé. En effet les pratiques professionnelles de mise à disposition de ces supports de diffusion d'information spécifique apparaissent différentes selon les dispositifs observés. Ici, deux espaces documentaires distincts ont été questionnés à travers l'analyse de l'offre de périodiques d'histoire proposée aux usagers. Cette première partie de l'étude a permis d'approcher les pratiques professionnelles des documentalistes, dans leur rôle de médiation de l'information produite par les périodiques. La deuxième partie s'intéresse aux usages de ce support d'information.

Mots-Clés Médiation; organisation du savoir; système d'information; dispositif documentaire; usage; périodique.

\section{Introdução}

Se os periódicos têm tradicionalmente um papel central na difusão do saber, porque «o meio de informação periódico é o vetor privilegiado da mediação de conhecimentos de um campo científico» (Couzinet, 2000), a evolução atual de sua forma de colocação à disposição, por exemplo « o periódico eletrônico como um novo meio de difusão da ciência » (Couzinet, 2000) tende a modificar os acessos para os usuários. Por outro lado estes periódicos não estão isolados na maior parte dos casos e estão combinados em dispositivos documentais quer eles sejam « físicamente reais »-como as bibliotecas ou os centros de documentação- ou mais virtuais como os portais, os sites, ou as plataformas reunindo bancos de dados bibliográficos ou os periódicos em si mesmos. 
Os documentalistas e bibliotecários, tratam a informação disponível nos periódicos mais usualmente na sua forma impressa que na sua forma digital. Com efeito, « é a diferença de percepção de suporte do documento, assim como a representação da diferença entre esses dois tipos de documentos, impresso e digital, que induzem à práticas profissionais que são em si, diferentes » (Gardiès, Fraysse, Courbières, 2007). No entanto, os profissionais põem ainda os periódicos à disposição dos usuários num espaço construído que na maioria das vezes inscreve o documento como objeto material para o qual o suporte prevalece sobre o conteúdo (Gardiès, Fraysse, Courbières, 2007), mas de forma diferenciada pela diversidade de usuários. Ora, a disponibilização dos periódicos, que tende a se multiplicar, altera ao mesmo tempo essas práticas profissionais e os usuários tradicionais. O que acontece então aos periódicos, na sua forma em papel como na sua forma digital? Há uniformização das práticas profissionais da colocação à disposição destes meios e da difusão desta informação específica? O tratamento da informação é diferenciado segundo o meio? Quais são os usuários que daqui resultam? Diferentes em função dos formatos solicitados?

Para responder a estas questões, de um ponto de vista teórico apoiamos nossa análise, por um lado sobre o papel dos periódicos na definição da necessidade e do uso da informação, e por outro lado, sobre a organização de saberes nos dispositivos documentais pelo viés das ciências da informação e da comunicação. De um ponto de vista empírico, nós pesquisamos numa primeira parte dois espaços documentais distintos, nas bibliotecas universitárias, a fim de tentar definir através destes exemplos as escolhas profissionais quanto ao tratamento dos periódicos de história postos à disposição. Na segunda parte tentamos abordar os usos e sua dependência, ou não, dos suportes. Para esta pesquisa, escolhemos limitar-nos à análise destes dois dispositivos documentais e ao tratamento de três periódicos de História ${ }^{1}$ : um periódico de vulgarização-a História, um periódico sobre o ensino da disciplinaHistoriadores e Geógrafos, e enfim um periódico de história especializadaHistória e sociedades rurais. Procuramos assim definir se a organização do saber que é proposta, através do tratamento documental é significante em termos de mediação. Esta reflexão dá continuidade ao trabalho de pesquisa apresentado no $1^{\circ}$ Colóquio mediações e usos de saberes da informação: um diálogo França - Brasil (Rede MUSSI), intitulado «Organização do saber e mediação documental: exemplo do tratamento de periódicos de história em duas bibliotecas universitárias » (Senié-Demeurisse, Fabre, Gardiès, 2008).

\section{1- Contexto de análise: dispositivos documentais}

\footnotetext{
${ }^{1}$ Títulos presentes nos dois dispositivos documentais analisados
} 
Estudamos, para esta pesquisa, duas estruturas específicas: o estabelecimento de Ensino superior agrícola (a Enfa) e uma universidade do Ensino superior e da pesquisa. A

Ainsi sont dispensés des enseignements de niveau licence dans les domaines de l'agro-équipement, de la qualité, de l'environnement, de l'amélioration génétique des plantes, ainsi que des enseignements en Master dans les domaines de la gestion des espaces de montagne, de la biologie des écosystèmes, des sociétés rurales, de l'alimentation.

Enfa tem por missão principal a formação de professores de liceus agrícolas públicos franceses de todas as disciplinas, e se encarrega ainda das formações de nível LMD $^{2}$. Portanto são dispensados a formação ao nível de licenciatura nos domínios de agro-equipamento, da qualidade, do meio ambiente, do melhoramento genético de plantas, assim como a formação do Mestrado nos domínios da gestão de espaços em montanhas, da biologia de ecosistemas, de sociedades rurais, da alimentação. A parte principal do acervo documental de sua biblioteca é constituida por informações científicas e técnicas (ICT). Esse acervo é constituido de 30 000 documentos, 340 assinaturas correntes e 150 suspensas. Essas assinaturas são constituídas ao mesmo tempo de jornais de informação geral e de periódicos culturais, mas a maior parte dos títulos diz respeito às disciplinas dos cursos e às temáticas de pesquisa presentes na escola. A Universidade, não oferece formação na área de Letras e das Ciências Humanas. A biblioteca de História, Artes e Arqueologia desta universidade possui um acervo muito especializado. Os domínios cobertos são a história, da Antiguidade até hoje, a história da arte, da pré-história até hoje, a arqueologia, as artes plásticas e as artes aplicadas. A composição deste acervo é constituida por 41000 monografias, 88 assinaturas correntes, 480 assinaturas suspensas, 3823 dissertações de Mestrado.

Os dispositivos documentais que observamos para esta pesquisa em dois momentos, oferecem assinaturas compostas ao mesmo tempo de jornais de informação geral e de periódicos culturais e especializados. As universidades onde estes dispositivos estão localizados, apresentam um domínio de especialização diferenciado, sendo que as duas colocam os periódicos de história à disposição de seus usuários. O acesso a essas duas estruturas assim como à consulta no local são livres. O empréstimo está reservado aos leitores registrados. O público é composto por professores pesquisadores de diferentes disciplinas e em sua maior parte de estudantes. As duas bibliotecas participam cada uma ativamente de uma rede documental o que determina em parte as escolhas e prioridades no oferecimento dos documentos. Para pesquisar a forma como os saberes estão organizados, analisamos a oferta que esses dois dispositivos propõem aos usuários através de três periódicos, escolhidos como representativos de cada um dos três eixos no âmbito da disciplina de história.

\footnotetext{
${ }^{2}$ Licenciatura, mestrado, doutoramento
} 


\subsection{Os periódicos de história nesses dispositivos}

Nossa seleção baseou-se em três periódicos diferentes pelos seus projetos editoriais e público a que se destina. Cada um tem uma forma particular de difusão ligada ao seu uso.

A História ${ }^{3}$ é um periódico de vulgarização. Mensal é editada pela sociedade de edições científicas, e publica há três décadas, artigos escritos por historiadores. Ele propõe abordar os grandes temas da história e de os repensar apresentando pontos de vista de historiadores contemporâneos. Estas questões apaixonam um vasto público de leitores, é encontrado em bibliotecas, e também vendido em bancas de revistas.

Historiadores e geógrafos é um periódico generalista da disciplina. Estuda os temas relativos ao ensino da história e da geografia nos liceus e nos colégios. A Associação de Professores de História e de Geografia do ensino Público (APHG) fundada em 1910 edita-o quatro vezes por ano. Destinado aos professores do ciclo secundário, apresenta habitualmente uma seção "Pedagogias".

História e sociedades rurais é um periódico especializado que trata da história dos campos do Neolítico até aos nossos dias. Ele responde aos critérios de cientificidade, quer dizer, ele é feito por pesquisadores para pesquisadores. Publica trabalhos que exprimem uma ambição cognitiva, e é uma ferramenta essencial para o debate científico cujos artigos são submetidos à aceitação sendo indexado em grandes bancos de dados (Boure, 1995; Couzinet, 1997). O primeiro número, publicado pela Associação de História de Sociedades Rurais criado em Maio de 1993, foi publicado em 1994. Com periodicidade semestral, ele beneficia-se do apoio do Centro nacional da Pesquisa Científica, do Ministério da Agricultura, do Centro de Pesquisa sobre as Sociedades e Culturas do Oeste (universidade Rennes 2), do Centro de História de Regulações e de Políticas Sociais (universidade de Angers), da universidade de Paris 7.

Esses três periódicos têm cada um um site na Internet e dispõem igualmente de versão eletrônica limitada para os não assinantes. Diferentes na sua apresentação, os próprios sites oferecem os mesmos tipos de acesso à informação. Além dos sumários simples ou enriquecidos, eles propõem em geral índices por nomes de autores e por palavraschaves. O periódico "História e sociedades rurais" publica certos artigos em texto integral, e é acessível através do portal CAIRN. ${ }^{4}$ O exame do seu tratamento permite questionar a sua colocação à disposição via práticas profissionais particulares e isso em função de seu nível, de seu formato respectivo e dos usuários específicos.

\section{2- Periódicos para difundir a informação}

\subsection{Periódico}

\footnotetext{
${ }^{3}$ Esta revista no início foi criada em 1973 por Michel Winock e as edições Seuil

${ }^{4}$ CAIRN : Portal propondo a publicação e a difusão de periódicos de ciências humanas e socais. A Biblioteca Nacional da França associou-se a este projeto.
} 
É consenso que a publicação em série é uma publicação que se sucede no tempo, durante um período que, de antemão, não é limitado e que pode aparecer sob qualquer suporte, volumes, fascículos, geralmente identificados de maneira cronológica. Reagrupamos sob esse termo genérico os periódicos propriamente ditos (jornais, periódicos). (Provansal, 1997).

Na nossa disciplina, as ciências da informação e da comunicação, o periódico foi estudado como suporte de mediação científica do ponto de vista da sua definição (Boure,1993; Bourre, 1995), de suas evoluções, do suporte impresso ao suporte eletrônico, ao mesmo tempo nas consequências que essa mudança técnica induz nos modos de acesso aos conteúdos (Courbières, 1997) e nos modos de elaboração destes últimos (Couzinet, 1999). O periódico é um objeto mediador que enquanto tal interessa às CIC, mas é também a instância que dá visibilidade às investigações dirigidas e portanto de sua avaliação e da avaliação de seus autores. Assim ele se encontra investido de um papel político e social visando a afirmar, ao mesmo tempo, o posicionamento dos pesquisadores e o de uma disciplina, tanto no âmbito nacional quanto muitas vezes internacional. O desenvolvimento do portal de recepção de períódicos traz um valor agregado. « Com efeito a coabitação com outros periódicos traz uma co-valorização apoiada por um trabalho documental que completa o serviço dado ao leitor. Assim o períódico não funciona mais como um objeto isolado mas como uma parte de um todo que tira proveito do que o acompanha ». (Senié-Demeurisse, Roux, Couzinet, 2007 : 9).

O periódico suporte de comunicação da informação tem um lugar central no âmbito do dispositivo documental. Este lugar não pode ser pensado sem referência ao que faz a sua essência: a necessidade e o uso de informação.

\subsection{Necessidade e uso de informação}

Com efeito, o sistema de informação em sua totalidade é destinado a responder às necessidades de informação, de usos variados empregados, da informação que eles obtêm, usos multiformes. Mas a tomada de consciência da necessidade de informação não é sempre tão evidente quanto possa parecer, quando ela é necessária à elaboração de um objeto de pesquisa de informações. Conhecer a necessidade de informação permite compreender porque é que os usuários engedram-se num processo de pesquisa de informação. O sistema tem de satisfazer a necessidade mas tem de ajudar igualmente o utilizador a definir outras necessidades. Podemos assim qualificar a necessidade de informação de « extensiva ».

Os termos usos e utilizadores levam muitas vezes a uma certa ambigüidade pois eles são empregados como conceitos linguísticos e não como conceitos científicos. Assim quando se fala de usos na linguagem corrente isso pode significar hábitos, práticas, comportamentos, atitudes. Da mesma maneira, necessidade e uso determinam o comportamento do 
usuários, mas é mais o uso do objetos que o uso de informações que até hoje tem sido estudado, quer dizer, que as maneiras de o fazer são abordadas na sua relação com o sistema. No entanto, o uso não se reduz à técnica. «Falar de uso, é evocar ao mesmo tempo o funcional (como nos servimos disto?) e o simbólico (o que está em jogo?) [...] O uso é um elemento da prática cultural, o que diz respeito à situações ou a sujeitos sociais são confrontados com dispositivos concebidos por outros e não por eles » (Jeanneret, $2008:$ 43-44).

Etimologicamente, a palavra « uso », derivada do latim usus ou us, designa uma prática considerada como normal numa dada sociedade, e o conjunto de hábitos de uma sociedade No século XIII a palavra toma igualmente o sentido de uma taxa que se paga para se poder servir de alguma coisa. A partir do século $X V$, ela designa, por um lado, o direito real que permite utilizar o que é do outro e por outro, a prática habitual de qualquer coisa. «Por extensão do sentido de «prática social », a palavra designa (1666, Molière) a experiência do mundo, as-boas maneira que ela dá depois no século XIX, e que equivale a « hábito particular » (de um grupo) 》(Rey, 1995 : 2202). Nas ciências da informação e da comunicação, esta noção toma um sentido bem particular. Cacaly,por exemplo, define o uso como um " processo informacional que consiste em fazer (ler, recolher, trocar, olhar, escutar, tocar, etc...) qui satisfasse un besoin d'information, l'information subsistant après usage ». com 0 material informação para se obter um efeito que satisfaça uma necessidade de informação, a informação que permanece após o uso", (Cacaly, 2004 : 243). Para este autor, o usuário é portanto a pessoa que age para chegar a satisfazer sua necessidade de informação. O uso é uma atividade social, uma maneira de fazer, uma arte de fazer. É uma atividade que, pela sua frequência, passa a ser normal até mesmo corrente no âmbito de um sistema (Coadic, 1997 : 19).

O uso faz aparecer lugares, circulações, produções muitas vezes invisíveis, por serem escondidas ou efêmeras. Por outro lado « a noção de uso [...] foi há muito tempo associada a um polo receptor oposto a um polo conceptor, à esfera de paixões e de singularidades individuais, oposta à esfera de organizações [...] mas ela encontrou os meios de saída dessas pré-estruturações aproximando-se de uma problemática de mediações e afrontando a complexidade de dados que ela gera por suas atitudes empiristas ». (Souchier, Jeanneret, Le Marec, 2003 : 39). Os fenômenos ligados ao uso recobrem igualmente os discursos. Assim, eles « oferecem o interesse de associar à primeira tentativa, no objeto de análise dos comportamentos, discursos, objetos e proibem a possibilidade de pensar tranquilamente noções proprietárias ao abrigo da barreira que separa a ciência do senso comum ». (Souchier, Jeanneret, Le Marec, 2003 : 40).

Para J. Mahoudeau, o ambiente de uso pode ser entendido por diferentes ângulos: o contexto social, a estrutura cognitiva e o lugar de utilização (Mahoudeau, 2006 : 174).

Para completar as diversas abordagens do conceito de uso, podemos nos referir a Cacaly que propõe qualificá-los. Para ele, o não-uso é um 
fenômeno racional que pode resultar em imagens negativas no sistema de informação e no pessoal e estar na origem de uma « infofobia ». O que pode também ser a consequência do baixo uso de técnicas e de sistemas de informação. Os maus usos declinam- se por este autor em « mauuso » que diz respeito a uma persistência em utilizar fontes eletrônicas de informação inapropriadas ou programas inadaptados, « ab-uso » que diz respeito à adição ou à dependência, « usos por desvios » como por exemplo a deterioração, o roubo ou a fraude. As lógicas de uso que dizem respeito ao mesmo tempo a um uso da informação, que pode aparentarse a uma captura, e a um uso duma técnica de informação, que detem uma variedade de formas de usos que vão desde a recusa, passando pelo não-uso, ou por tomar a pista do desvio (Cacaly, 2004 : 243).

Para resumir estas diversas abordagens podemos dizer com Mahoudeau que o uso pode ser definido como o que realmente fazem os usuários de instrumentos de mediação que eles manipulam (Mahoudeau, 2006). Essas ferramentas, dentre as quais o periódico pode ser incluído, adicionado da intervenção humana de um mediador, são agenciadas num dispositivo documental em função de uma organização do saber frequentemente pré-determinada.

\subsection{Organização do saber, dispositivo documental e mediação}

O espaço documental pode ser considerado como o pilar do dispositivo documental. Ele é ao mesmo tempo uma ordem de conhecimentos, resultante da normalização extraída de sistemas classificatórios e uma concepção da relação com o público. Ele é assim o território privilegiado da organização do saber. A gestão de tal dispositivo necessita da organização de diferentes entidades: espaços, instrumentos de pesquisa, de informações e a comunicação da informação contida nestes diferentes objetos. Lembramos tratar-se, para o profissional da informação -documentação, de comunicar informações para que o usuário construa seus próprios conhecimentos. No entanto, esta mediação só é possível graças à construção de um espaço específico, o qual possua uma organização que faça sentido. A colocação de uma organização do saber necessita de « uma instância que assegure, na comunicação e na vida social, a articulatção entre a dimensão individual do sujeito e de sua singularidade e a dimensão coletiva da sociabilidade e da ligação social » (Lamizet, Silem, 1997), quer dizer, uma mediação.

« O termo mediação designa [...] o espaço denso de construções que são necessárias para que os sujeitos, envolvidos na comunicação, determinem, qualifiquem, transformem os objetos que os reunem, e estabeleçam assim suas relações.» (Jeanneret, 2007). Nas bibliotecas e centros de documentação, existem dispositivos de mediação técnica como as classificações, os catálogos, a sinalética, folhetos que favorizam o livre acesso e a autonomia dos seus públicos. Todos esses dispositivos técnicos são o resultado de uma mediação humana. O gosto pela pesquisa de 
informação não nasce somente da familiaridade material de dispositivos. Estabelecer uma mediação seria o mesmo que, de certa maneira, os processos de apropriação pudessem existir no interior dos seus usos, particularmente no âmbito do tratamento da informação, pois « a língua documental constitue uma das chaves do princípio de mediação inerente ao processo de indexação e estabelece o contrato específico da situação de comunicação documental » (Courbières, 2008). O que se passa com a informação difundida via periódicos especializados? Dito de outra maneira, a mediação pode facilitar os usos?

\section{3- O exemplo de periódicos de história no âmbito dos dispositivos documentais}

\subsection{Coleta de dados: método}

Para tentar compreender como os acessos aos periódicos, enquanto mediadores de conhecimentos, tendem a se modificar para os usuários e como os profissionais da informação tratam esta informação assim disponível sob diferentes formatos (impresso ou digital), apoiamo-nos num primeiro momento num inventário de formas observáveis como a organização do espaço documental e o tratamento da informação recuperando os procedimentos implementados. Num segundo momento a análise apoia-se na observação e no questionamento das práticas profissionais, através de um questionário e de entrevistas em cada uma das duas instituições. Esta multiplicação de métodos de investigação permite-nos um olhar cruzado.

Finalmente, a observação dos usos incide, como o sugere BeguinVerbrugge, não unicamente sobre a satisfação dos usuários mas «sobre as estratégias dos atores, sua natureza, sua concorrência, sua complementaridade, o que supõe análises quantitativas apuradas sobre as atitudes dos usuários mas também uma análise dos modos de repartição e de realização das tarefas documentais nas diferentes fases da sua realização, com uma avaliação de sua incidência sobre a apropriação final » (Beguin-Verbrugge, 2002 : 335). No entanto, os fenômenos ligados ao uso, recobrem ainda discursos. Eles incluem todas as formas de situações onde circulam as representações (Davalon, Lonnet, Jeanneret, Le Marec, Souchier, 2003 : 40).

Para cercar todos os usos de um sistema de informação documental, escolhemos então uma abordagem híbrida o que autoriza aliar a observação dos usuários e dos traços de suas atividades em complemento à análise de discursos que eles têm sobre os sistemas e as ferramentas que os cercam.

Trata-se pois em primeiro lugar, de cercar a mediação proposta no âmbito do dispositivo documental, depois tentar aproximar, através da comparação de dois dispositivos documentais, a disponibilização dos periódicos de história em termos da valorização, da identificação e de acesso. Destacaremos o tratamento (efetuado, referência, localização, 
resumo, texto integral etc...), para compreender em que é que ele pode revelar uma potencial adequação entre o trabalho do profissionais e as práticas dos usuários. A mediação pode com efeito ser mais ou menos alcançada.

\subsection{Resultados}

As observações incidindo sobre as duas estruturas documentais, foram feitas em paralelo destacando o arranjo de periódicos de história, a produção e a difusão de documentos secundários e os links de acessos digitais a esses periódicos. Um questionário prévio às entrevistas, endereçado aos documentalistas das duas estruturas, permitiu conhecer num primeiro momento suas formas de funcionamento e daí deduzir uma grade de questões para as entrevistas. Estas últimas, (quatro entrevistas), incidiram sobre o tratamento e a disponibilização da informação dos três periódicos de história selecionados.

Em termos de coleção, as escolhas de assinaturas são feitas por professores e pesquisadores de diferentes cadeiras. Os profissionais da informação - documentação tornam-se bastante úteis porque eles asseguram uma vigília sobre os títulos disponíveis. No dispositivo documental não especializado em história, os profissionais esforçam-se por assinalar a informação contida nos periódicos de duas maneiras. A primeira consiste na criação de um documento secundário mensal nomeado «Boletim sinalético das obras» que, através de uma classificação temática, dá indicações aos usuários sobre os títulos dos artigos. A segunda, trata-se de um portal documental, acessível na Intranet e na Internet, que permite oferecer entre outros serviços, uma lista de periódicos disponíveis com links para seu próprio site desde que ele exista.

Podemos notar que os profissionais desta estrutura procedem a uma valorização específica da informação dos periódicos. Com efeito, para tornar contínua a identificação própria ao boletim sinalético, o descarte está integrado ao catálogo do banco de dados interno. Estas referências bibliográficas, acrescidas de uma palavra chave temática vêm então juntar-se às instruções do catálogo e são colocadas online. Em termos de tratamento da informação, podemos notar que uma indexação parcial dos artigos é efetuada sob forma de instruções bibliográficas através de uma rede documental específica e integrada ao catálogo local.

Para a difusão da informação contida nos periódicos, o centro de documentação disponibiliza suas fontes através de um site onde seu catálogo pode ser pesquisado online e documentos secundários consultáveis e tele-descarregáveis tais como o buletim sinalético supracitado, a lista de títulos de periódicos presentes na biblioteca, se existem, e os links com o site Internet do periódico. 
Ao contrário, em termos de tratamento da informação, na outra biblioteca universitária estudada, os artigos não estão indexados; só estão disponíveis os índices dos próprios periódicos. Por exemplo, para o periódico de história e sociedades rurais, a existência de tabelas decenais é mencionada no catálogo. Elas só são consultáveis no local.

Nas duas instituições, a disposição dos periódicos no espaço documental parece refletir uma preocupação de valorização. Um espaço Ihes é reservado logo na entrada da biblioteca, de forma a favorecer a leitura. Sobre os expositores, o último número do periódico é apresentado frontalmente e os números precedentes estão arranjados no compartimento correspondente e os anteriores são arquivados. Os periódicos estão distribuídos no espaço documental seguindo uma classificação alfabética; o acesso é facilitado pela afixação de listas alfabéticas no início dos expositores/estantes.

As fontes numéricas ligadas aos periódicos são acessíveis pelo portal da universidade, o Serviço Comum de Documentação (SCD) ${ }^{5}$ fazendo parte da rede de Bibliotecas das Universidades. A pesquisa e o acesso à informação se faz por intermediário seja de um catálogo coletivo (catálogo comum da rede de Bibliotecas das Universidades) seja do catálogo

de periódicos eletrônicos em texto integral assinado pela universidade. Este catálogo coloca as instruções referentes ao periódico, ao estado da coleção, à disponibilidade, aos outros suportes e informações diversas. Os acessos aos recursos eletrônicos são possíveis em todos os casos, para certas informações digitalizadas (sumário, resumo de artigos ou artigos em texto integral), por intermédio do site dos periódicos acessíveis diretamente seja qual for o local da consulta.

Os usos relacionados a estes três títulos de periódicos puderam ser destacados a partir de entrevistas incidindo sobre as práticas dos usuários, em particular pelas consultas de documentos no local mas também sobre sua prática de leitura e / ou de pesquisa de informação.

Dois grandes tipos de funcionamento parecem se desenhar. No que diz respeito aos professores e aos pesquisadores que são principais usuários do periódico Historiadores \& geógrafos e do periódico História e sociedade rural, eles afirmam apoiar- se sobre a identificação produzida pelos documentalistas através do tratamento da informação que os informa do conteúdo do documento e da sua disponibilidade. É por este viés que eles fazem uma primeira seleção e só se deslocam para consultar, fotocopiar ou pedir emprestado o artigo a partir de referências bibliográficas assinaladas.

O público de estudantes parece consultar diretamente os números de periódicos, mas também pesquisa o catálogo da biblioteca sobre a prescrição dada pelos professores ou ainda por seu trabalho bibliográfico regular.

No que diz respeito aos usos do periódico de História, trata-se mais de uma leitura de lazer que parece corresponder ao mesmo tempo a uma

\footnotetext{
${ }^{5}$ O serviço comum de documentação está encarregado de realizar a política documental da Universidade
} 
vigilância precisa (os leitores passam na biblioteca no momento da data de publicação prevista dos números), para uma leitura regular que se faz fora da biblioteca o que necessita de um empréstimo. Isto é confirmado por uma taxa mais elevada de empréstimos deste periódico em relação aos outros. Por outro lado, ao contrário dos dois outros periódicos, só muito raramente existe uma procura dos antigos números da coleção, em oposição às práticas comuns aos pesquisadores deste domínio.

Une tendance qui paraît ressortir de notre investigation : les sites Internet des périodiques concernées sont assez peu consultés. Dans tous les cas ils ne semblent pas constituer le point d'entrée des recherches d'informations pour les périodiques d'histoire observées.

Uma tendência que parece sobressair da nossa investigação: os sites Internet dos respectivos periódicos são muito pouco consultados. Em todo o caso eles não parecem constituir o ponto de entrada das pesquisas por informações, nos periódicos de história observados.

\subsection{Organização do saber, mediação e uso}

Mesmo que limitado à duas instituições, as observações nos permitem dizer que enquanto Paul Otlet, desde 1934, destacava a necessidade do tratamento da «unidade informacional » (Otlet, 1934) para facilitar o uso, os profissionais da informação hoje, face à diversidade de formatos disponíveis, tendem a se limitar, no caso dos periódicos, a uma disponibilização no espaço, valorizando o suporte em detrimento de um real tratamento documental do conteúdo.

As práticas profissionais apoiam-se sobretudo em produtos simplificados de tratamento como, por exemplo, os índices produzidos anualmente pelos editores ou os sites de periódicos que propõem informação útil paralelamente a outros tipos de informações. No entanto, os profissionais da informação produzem documentos secundários que se limitam a uma identificação mas não procedem a uma análise documental completa. É o caso, por exemplo, da indexação produzida pelas redes documentais, que se mantém parcial, os boletins sinaléticos para divulgação, as listas alfabéticas etc...

Nos casos estudados, os profissionais apóiam-se mais na organazação no espaço dos suportes de saberes, em detrimento de uma interpretação e de uma tradução da informação que colocaria em uso as linguagens documentais. Contudo «a utilização de uma linguagem documental tem por vocação transformar a comunicação documental numa comunicação perfeita na qual as duas instâncias deste processo atribuem uma mesma significação aos sinais manifestados » (Courbières, 2010), favorizando assim um diálogo entre a colocação à disposição da informação e as solicitações dos usuários.

Percebeu-se também que a organização de dispositivos documentais especializados, neste estudo sobre a temática da história, não parece favorecer um tratamento documental adaptado visto que nesse caso também é a identificação que predomina, como demonstra a classificação 
alfabética de periódicos que não considera, por exemplo, o nível científico. Assim, na biblioteca de história, o periódico científico ladeia a revista de vulgarização e não se beneficia de um tratamento específico.

Do ponto de vista do uso, tudo se passa como se existissem fortes pressupostos referentes às competências dos usuários e como se a versão eletrônica tornasse obsoleta a análise documental. Ora, o documento, midia desta informação, não é sinônimo de mediação, com efeito «o suporte tem de ser entendido no sentido da tela, quer dizer, uma superfície não contendo nenhum elemento significante patente » (Gardiès, Fraysse, Courbières, 2007).

A análise dos usos, no sentido de uma atividade sobre a informação significante para o usuário, pode então permitir aproximar aquilo em que a utilização dos instrumentos de mediação podem responder às necessidades de informação expressas ou latentes. No entanto este aspecto, nas situações trazidas aqui, só pôde ser abordado parcialmente. Os primeiros resultados confirmam contudo a importância de uma mediação da informação baseada num tratamento direcionado como elemento facilitador do acesso à informação especializada.

\section{Conclusão}

Esta pesquisa, mesmo que limitada a um objeto restrito, permitiu destacar similaridades no tratamento de periódicos de história observados em duas bibliotecas a nível de sua colocação no espaço, de seu tratamento reduzido à identificação, via documentos secundários, e de seus usos. Em paralelo, e como o mostram outros trabalhos, « o carácter crescente das consultas aos recursos eletrônicos [...]inscreve-se numa dinâmica de apropriação, pelos pesquisadores, de modalidades desmaterializadas da publicação científica » (Boukacem-Zegmouri, Kamga, 2008). Apesar disso, a especialização de dispositivos documentais não parece induzir a uma análise documental de periódicos adaptados às necessidades específicas dos usuários. Um estudo mais orientado sobre as práticas dos usuários permitiu-nos começar a apurar a questão do papel mediador das práticas profissionais de documentalistas, mas falta ainda aprofundar esta observação especialmente sobre os suportes digitais.

\section{Referência}

Beguin-Verbrugge, 2002. Le traitement documentaire est-il une énonciation? In Actes du XIIIe congrès national des sciences de l'information et de la communication (7-9 ocotbre 2002 ; Marseille).Rennes : SFIC, p. 329-335.

Boukacem-Zegmouri Chérifa, Kamga Rachel, 2008. La consultation de périodiques numériques en bibliothèque universitaire. Bulletin des Bibliothèques de France. Paris. n³, p. 48-60

Boure Robert, 1993. Le territoire incertain des périodiques scientifiques. Réseaux, n58, p. 93-105. 
Boure Robert, 1995. Le statut des périodiques dans la communication entre chercheurs. Périodique des périodiques, $\mathrm{n}^{\circ} 20$.

Cacaly Serge, 2004. Usage. In Dictionnaire de I'information sous la dir. de Cacaly. Paris : Nathan. 2004. p 243.

Courbières Caroline, 1997. Nature et fonction de l'hypertexte dans les périodiques électroniques sur le Web : quand la structure fait signe. In Actes du séminaire annuel. Toulouse : Université Paul Sabatier-Lerass, vol.5, p. 20-33.

Courbières, Caroline In Gardies, Cécile (Dir.) (2010). Les langages documentaires. Les concepts fondamentaux en information documentation. Toulouse : éditions Cépadues. (accepté, à paraître)

Couzinet Viviane, Bouzon Arlette, 1997. Usages et représentations de la périodique scientifique électronique chez les doctorants. In Cap a la societat digital : un món en contínua transformació, 23-25 oct.1997. Barcelone : Socadi, p. 391-403.

Couzinet Viviane, 1999. La périodique électronique de sciences humaines et sociales : éléments pour une définition. RIST, vol. 9, n², 1999, p.119132.

Couzinet Viviane, 2000. Médiations hybrides: le documentaliste et le chercheur en science de l'information.- Paris : ADBS. 340 p.

Fabre, Isabelle et Gardiès, Cécile. 2008. L'accès à l'information scientifique numérique : organisation des savoirs et enjeu de pouvoir dans une communauté scientifique. Sciences de la société, octobre, $\mathrm{n}^{\circ} 75$, p. 85-99.

Gardiès, Cécile, Fraysse, Patrick, Courbières, Caroline. 2007. Distance et immédiateté : incidences du document numérique sur le traitement de l'information. Etudes de communication, n³0, p.71-81.

Jeanneret Yves. 2007. In L'écriture des médias informatisés : espaces de pratiques. Tardy, Cécile (dir.), Jeanneret, Yves (dir.). Paris: Lavoisier, 222 p. (Communication, médiation et construits sociaux).

Le Coadic Yves-François. 1997. Usages et usagers de I'information. Paris : Nathan. 128 p. (Collection 128 - information-documentation).

Le Coadic Yves, François. 1998. Le besoin d'information : formulation, négociation, diagnostic. Paris: ADBS. (collection Sciences de l'information).

Le Marec Joëlle. 1997. Sociologie des pratiques informationnelles. In Dictionnaire de l'information et de la Communication sous la dir. de Cacaly. Paris : Nathan. 1997. p 538-542.

Mahoudeau Julien. 2006. Médiation des savoirs et complexité. Paris : L'Harmattan. 
Médiation. In Dictionnaire encyclopédique des sciences de l'information et de la communication / sous la dir. de Bernard Lamizet et Ahmed Silem. Paris : Ellipses Marketing, 1997. p. 364.

Otlet Paul, 1934. Traité de documentation : le livre sur le livre. Bruxelles, éditiones Mundaneum.

Poissenot, Ranjart. 2005. Usages des bibliothèques: approche sociologique et méthodologie d'enquête. Villeurbanne: Presses de l'ensibb. 350p.

Provansal Antoine. Publication en série In Dictionnaire encyclopédique de I'information et de la documentation sous la dir. de. Serge Cacaly Paris : Nathan.1997. p 477-479.

Senié - Demeurisse, Josiane, Fabre, Isabelle, Gardiès, Cécile (2008). Organisation du savoir et médiation documentaire: exemple du traitement des périodiques d'histoire dans deux bibliothèques universitaires. ANAIS $2008: 1^{\text {er }}$ Colloque médiations et usages des savoirs de I'information : un dialogue France - Brésil (Réseau MUSSI). Instituto de Comunicaçao e Informaçao Cientifica e tecnologica em Saude ICICT/FIOCRUZ, Rio de Janeiro, 4-7 novembre 2008, p. 379-392.

Senié-Demeurisse Josiane, Roux Sabine, Viviane Couzinet. Périodiques scientifiques électroniques : contribution a une analyse de leurs mutations typologiques. Colloque International EUTIC 2007. Enjeux et usages des TIC. Médias et diffusion de l'information : vers une société ouverte. Athènes 7-10 novembre 2007. p343-352.

Souchier, Jeanneret, Le Marec, 2003. Lire, écrire, récrire : objets, signes et pratiques des médias informatisés. Paris: Bibliothèque publique d'information. 350 p. (Etudes et recherche).

\section{ANEXO 1}

\section{A História}

http://www.histoire.presse.fr/

Acesso aos sumários e pesquisa nos arquivos por palavras chaves. Acesso ao texto de artigos de números à venda, acesso aos arquivos (texto integral de artigos) por meio dum código de assinante.

\section{Historiadores \& geógrafos}

http://www.aphg.fr/AccueilHistoriensGeographes.htm

Acesso aos sumários e aos índices de artigos (desde 1990) com pesquisa por níveis e por tipo de artigos (pedagogia, dossiê, textos oficiais, bibliografia ...)

\section{História e sociedades rurais}


http://www.unicaen.fr/mrsh/socrurales/ahsr/index.php

Acesso ao sumário de números desde 1994 e a certos resumos. 